\title{
Effect of Carbaryl on the Histomorphometry of Kidney in Albino Rats
}

\author{
${ }^{1}$ Dr. Nagar Mahindra, ${ }^{2}$ Dr. Munglang Manumati \\ ${ }^{I}$ Professor and Head Department of Anatomy, Faculty of Medical Sciences, University of Delhi. C/o University \\ College of Medical Sciences \& Guru Teg Bahadur Hospital, Delhi-110095. \\ ${ }^{2}$ Senior Demonstrator (MBBS, M.D) Department of Anatomy, University College of Medical Sciences \& Guru \\ Teg Bahadur Hospital, Delhi-110095
}

\begin{abstract}
Carbaryl, a synthetic 1-napthyl-N-methyl carbamate, a broad-spectrum insecticide is being used commonly and extensively in commercial and agriculture land. It is sprayed on crops, fruits, vegetables, poultry and livestock. Therefore, it is a matter of great concern that food products consumed daily may be contaminated with the residue of this pesticide, resulting in serious toxic effects. Since the kidney excretes the primary metabolites of this drug, therefore the present work was conducted to study the histomorphological changes it may produce in the kidneys. In the experimental rats, a statistically significant decrease in the body weight was observed. Grossly the kidneys appeared normal in the experimental rats but on histological studies, the renal tubules appeared dilated with eosinophilic material in their lumen in most of the sites. There was a loss of normal architecture of the tubular epithelium. The cells appeared flattened with a loss of nuclei. There was a loss of brush border with apical blebbing towards the lumen in the proximal convoluted tubules. Inflammatory infiltrate was present in the mesangium. The interstitial tissue was infiltrated with inflammatory cells mostly polymorphonucleocytes.
\end{abstract}

Key words: Carbaryl, pesticides, kidney, renal tubules

\section{Introduction}

Exposure to Carbaryl, a synthetic pesticide, is a serious environmental problem, since a realm of uncertainty exists concerning its toxic effects on man. The presence of it's primary metabolite, 1-naphthol in the urine $\&$ faeces is used as a qualitative indicator of carbaryl exposure ${ }^{1}$.Workers inhaling carbaryl dust, excreted $74 \%$ of its metabolites like 1-naphthyl glucuronide and sulfate in urine. ${ }^{2}$ Carbaryl orally caused slight rise in free 1-naphthol and definite rise in conjugated 1-naphthol in the urine within forty-eight hours ${ }^{3}$. Dermal application of carbaryl emulsion, $4 \mathrm{hrs} /$ day for 4 wks caused an increase in the number of autophagous vacuoles in cells of proximal tubules in the kidneys, widening of the intra-alveolar septa, compensatory emphysema in the apical parts of the lungs and swelling of mitochondria and inflammatory infiltrations between cardiomyocyte fibers ${ }^{4}$. Occupational hazards reported in human are eye and skin irritation, increased risk of cancer, birth defects and neurological damage. ${ }^{5,6}$ Exposure to carbaryl, by any route, is probably hazardous to health although most observations are still inconsistence and conflicting. Literature on its effect on the renal morphology is sparse hence this is an attempt to observe the histo-morphological changes that might be occurring in the kidney in an experimental animal, rat.

\section{Material And Methods}

Inbred adult Wistar albino rats (150-200gm) were group housed with access to food and water ad libitum. The experimental rats, received $200 \mathrm{mg} / \mathrm{kg}$ body weight of carbaryl intraperitoneally, five days a week for thirty days. Control animals, received equal quantity of vehicle by the same route. The body weights were recorded before the onset of the experiment and prior to their sacrifice. The data obtained was tabulated and statistically analysed. All the animals were sacrificed within twenty-four hours of the last injection. The kidneys were removed after perfusion of the animal. Tissue was processed for paraffin sections $(7 \mu)$ and stained for light microscopy. Histomorphology of the kidneys was done

\section{Observations}

The experimental animals were very active and irritable immediately after the first dose of carbaryl. After half an hour of the drug administration, the rats started sneezing, shivering and developed tremors. There was a statistically significant decrease $(\mathrm{p}<0.001)$ in the mean body weight in the experimental rats (Table.1). 
Effect Of Carbaryl On The Histomorphometry Of Kidney In Albino Rats

\begin{tabular}{|c|c|c|c|c|c|}
\hline & Groups & Mean $(\mu)$ & SD & $\begin{array}{c}\text { p-value } \\
\text { (one way } \\
\text { ANOVA) } \\
\end{array}$ & $\begin{array}{c}\text { Significance } \\
\text { (Tukey's test at } \\
5 \% \text { level) } \\
\end{array}$ \\
\hline \multirow[b]{2}{*}{$\begin{array}{l}\text { Before the } \\
\text { experiment }\end{array}$} & Experimental & 165.30 & 13.96 & \multirow[b]{2}{*}{$>0.001$} & \multirow[b]{2}{*}{$\begin{array}{l}\text { Both the groups } \\
\text { are not } \\
\text { significantly } \\
\text { different from } \\
\text { each other }\end{array}$} \\
\hline & Control & 178.80 & 13.06 & & \\
\hline \multirow{2}{*}{$\begin{array}{l}\text { Prior to } \\
\text { sacrifice }\end{array}$} & Experimental & 301.40 & 40.21 & \multirow[b]{2}{*}{$>0.001$} & \multirow{2}{*}{$\begin{array}{l}\text { Experimental } \\
\text { group was } \\
\text { significantly } \\
\text { different from the } \\
\text { control group. }\end{array}$} \\
\hline & Control & 190.00 & 11.96 & & \\
\hline
\end{tabular}

Table 1: Comparison of body weight (gm) in experimental and control rats:

The renal tubules appeared dilated with eosinophilic material in their lumen. The lining epithelium appeared flattened with a loss of nuclei. The cells in the proximal convoluted tubules showed a loss of brush border with apical blebbing towards the lumen. Some of the glomerular tufts appeared collapsed with adhesions to the Bowman's capsule and there was a loss of normal architecture. There was a hypertrophy, and a hypercellularity of the parietal cells of the glomerulus usually called a cresent.The overlying visceral epithelial cells appeared hypertrophied. Interstitial areas showed edema and there was marked infiltration with inflammatory cells mostly polymorphonucleocytes (Fig-1)

Increase in mesangial cellularity with lobular accentuation of the glomerular architecture and mesangialization of peripheral capillary loops was seen, a sign of glomerulonephritis. Few glomeruli showed endocapillary proliferation and numerous polymorphonucleocytes within the capillary loops as well as within the mesangial area were seen (Fig-3). Subendothelial deposits were observed, more in the peripheral capillary lumen. Thickening of capillary walls caused by endothelial cell swelling resulted in pushing of the capillaries to the periphery. Accumulation of material between the endothelial cell and the basement membrane was also seen (Fig-2).

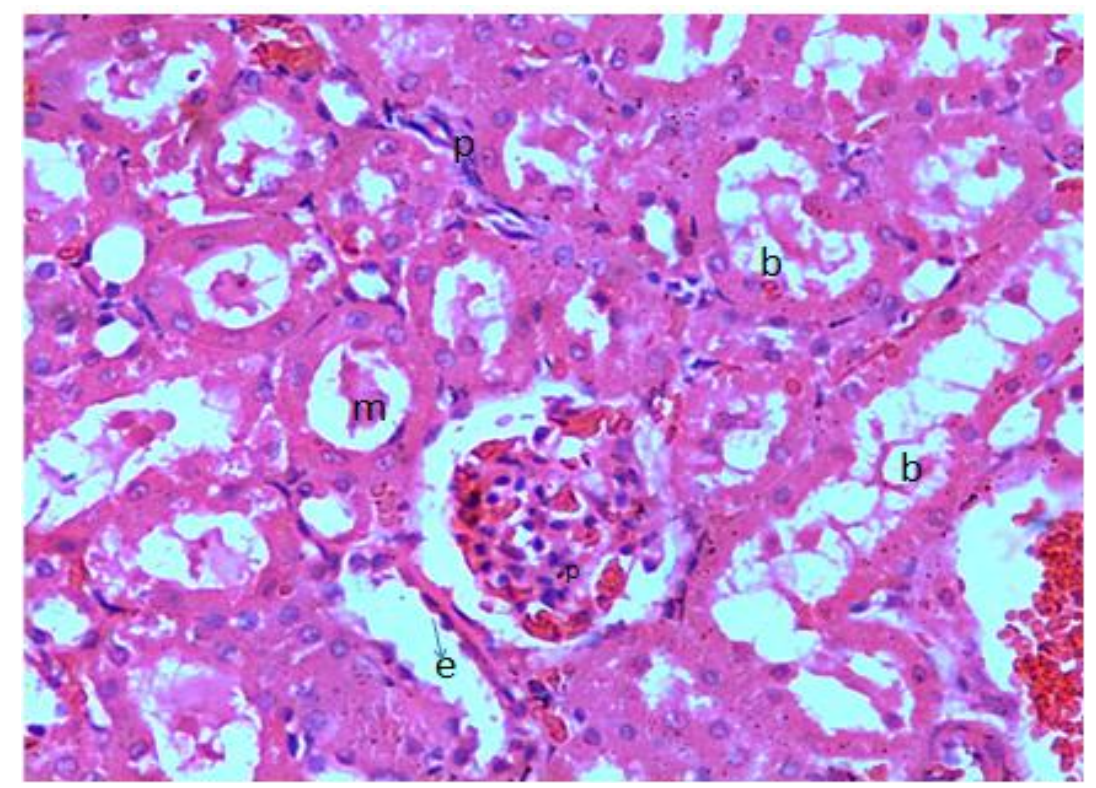

Fig:1. Photomicrograph of the tansverse section of kidney in an experimental rat showing dilated tubules with eosinophilic material (m) in their lumen. Flattened tubular epithelium (e) with a loss of nuclei and brush border, with apical blebbing (b). Interstitial tissue is infiltrated with inflammatory cells mostly polymorphonucleocytes. $(H \& E 200 X)$ 


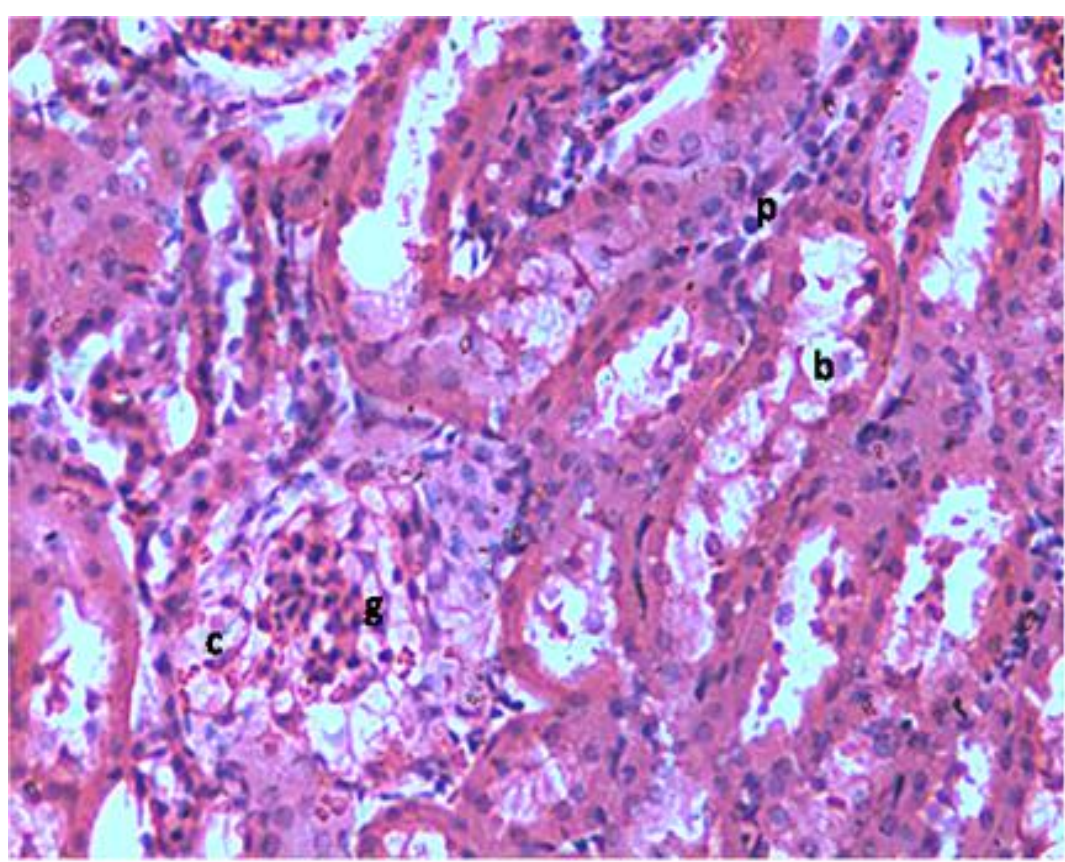

Figure-2. Photomicrograph of the tansverse section of the experimental rat kidney showing collapsed glomerulus $(\mathrm{g})$ with adhesion to the bowman's capsule and a hypertrophy and hypercellularity of the parietal cells of the glomerulus known as a cresent $\odot$. There is a loss of normal glomerular $(\mathrm{g})$ architecture. The tubular epithelial cells show apical blebbing(b) and interstitial areas show infitration with polymorphonucleocytes(p). $(H \& E 200 X)$

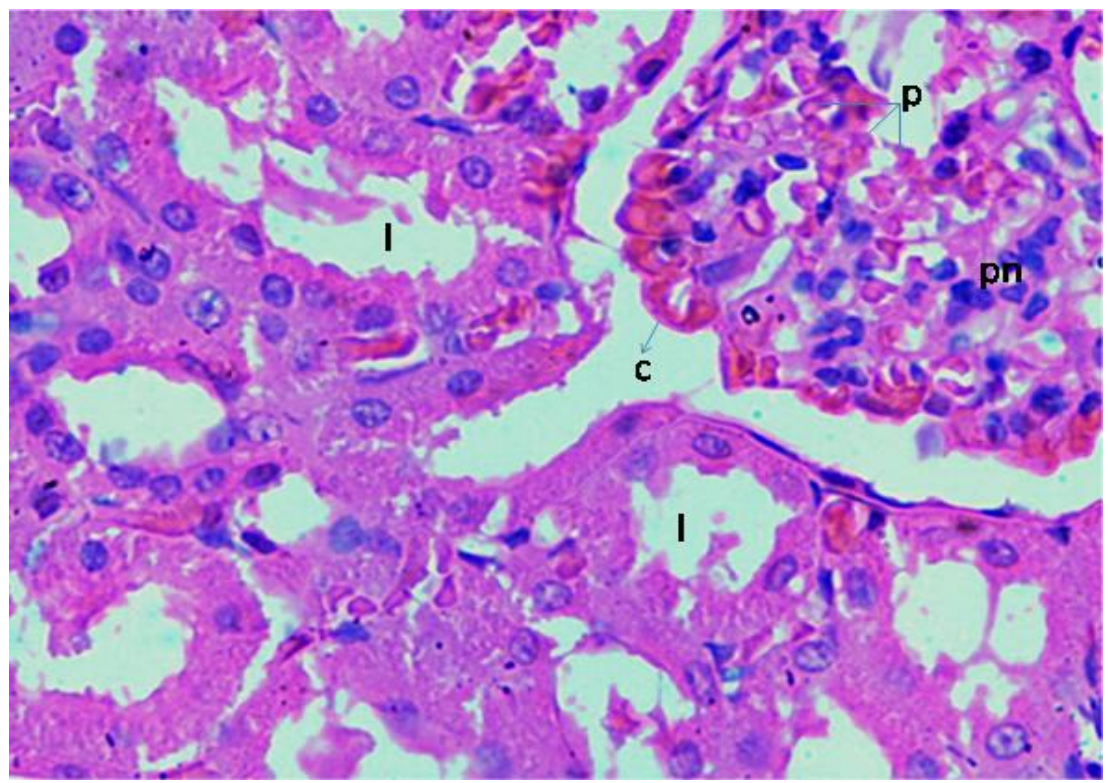

Figure-3. Photomicrograph of the tansverse section of the experimental rat kidney showing dilated tubular lumen (l) and glomeruli with endocapillary proliferation (p) and numerous polymorphonucleocytes (pn) in the mesangial area. There is increase in mesangial cellularity with lobular accentuation of the glomerular architecture and mesangialization of peripheral capillary loops@. ( $H \& E 400 X)$

\section{Conclusions}

In the present study, a statistically significant $(\mathrm{P}<0.001)$ decrease in the body weight in the experimental rats was found as compared to the controls. Earlier also a decrease in weight in an elderly miner who was exposed to carbaryl dust (10 per cent) for a period of eight months has been reported ${ }^{7}$

The flattened epithelium with a loss of nuclei and the loss of the brush border with apical blebbings in the proximal tubules observed in the experimental animals is suggestive of acute tubular necrosis. The dilated tubules with eosinophilic material in their lumen and marked interstitial infiltrate with inflammatory cells mostly polymorphonucleocytes is a characteristic of ischaemic acute tubular necrosis. An oral dose of carabryl 
in rats and dogs for a period of one year resulted in diffuse cloudy swellings of the kidney tubules ${ }^{3}$. Where as a dermal application in male Wistar rats for a month caused an increase in the number of autophagous vacuoles in cells of proximal tubules. ${ }^{4}$

At sites there was endocapillary proliferation with numerous polymorphonucleocytes within the capillary loops and the mesangial area in the glomeruli. The mesangial cellularity has increased in the lumen of the peripheral capillaries with thickening of capillary walls due to endothelial cell swelling and accumulation of material between the endothelial cell and the basement membrane.. Lobular accentuation of the glomerular architecture and capillaries are all features suggestive of glomerulonephritis. Even if a single glomerulus shows collapsing lesion it is proposed to warrant classification as collapsing glomerulopathy which has a poor prognosis resulting in proteinurea and a rapid loss of renal function.

We are constantly being exposed to this pesticide, which could be a slow, silent killer resulting in tubularinterstitial nephritis. The significance of this study in relation to current and future tolerance to carbaryl needs precautions and further study.

\section{References}

[1]. Best, E. M., Jr. and Murray, B. L. 1962 Observations on workers exposed to Sevin insecticide: a preliminary report. J Occup Med. Oct; 4: 507-517.

[2]. Knaak JB, Sullivan LJ, Wills JH. 1967. Metabolism of carbaryl in man. Toxicol Appl Pharmacol 10: 390.

[3]. Carpenter CP, Weil CS, Palm PE, Woodside MH, Nair JH, Smyth HF. 1961. Mammalian toxicity of 1-napthyl-N-methylcarbamate (Sevin Insecticide). J Agr Food Chem 9: 30-39

[4]. Toś-Luty S, Prezbirowska D, Latuszynska J, Tokarska-Rodak M. 2001.Histological and ultrastructural studies of rats exposed to carbaryl. Ann Agric Environ Med. 8: 137-144.

[5]. Wyrobeck AJ, Watchmaker G, Gordon L, Wang K, Moore D II, Whorton D. 1981. Sperm shape abnormalities in carbaryl-exposed employees. Environ Health Perspectives 40: 255-265.

[6]. Meeker J. D; Ryan L; Bar D. B; Herrick R. F; Bernett D. H; Bravo R; Hauser R. 2004. The relationship of urinary metabolites of carbaryl/naphthalene and chlorpyrifos with human semen quality. Environ. Health Persp.112: 1665- 1670.

[7]. Branch R.A and Jacoz E. 1986. Subacute neurotoxicity following long-term exposure to carbaryl. Am J Med; 80: $741-745$. 